\title{
A study of essential components of three types of Bituminous Materials in Mishraq sulfur Mine
}

\author{
Hala.S.J', Thaeir.A.H², Motea.O.A ${ }^{3 *}$ \\ ${ }^{1,2}$ Department of Chemistry, Collage of education for girl, University of Mosul, Mosul, Iraq \\ ${ }^{3}$ Mishraq sulfur state company, Mosul, Iraq \\ E-mail: ${ }^{1}$ hala.saad@uomosul.edu.iq. ${ }^{2}$ Thaer.abd@uomosul.edu.iq, ${ }^{3 *}$ alojmaniojmani@gmail.com
}

(Received February 11, 2020; Accepted May 14, 2020; Available online September 01, 2020)

DOI: 10.33899/edusj.2020.126679.1050, @ 2020, College of Education for Pure Science, University of Mosul.

This is an open access article under the CC BY 4.0 license (http://creativecommons.org/licenses/by/4.0/).

\begin{abstract}
:
The chemical constituentisof three types of bituminous materials found in different conditions in Mishraq sulfur Minewas studied. The FTIR spectroscopy showed reduce in the length of hydrocarbon chains from the intensity of paraffinic bands in bitumenous materials of Frasch sulfur Mine (BM) compare with natural bituminous materials (NB) and Bituminous materials which extracted in-depth about $200 \mathrm{~m}$ without exposing to Frasch process condition (BB). The percentage of asphaltene in (MB) which increases dramatically is found $63.64 \%$ compared with (BB) and (NB) which $37.37 \%$ and $14.28 \%$ respectively and a similar decrease in percentage petrolene (maltene) . A percentage of n-hexane fraction by silica gel chromatography of petrolene (MB) is $18.49 \%$ compared with (BB and N.B) are $25.06 \%$ and $47.05 \%$ respectively while the cyclohexane fractions of petrolene MB are four-time of N.B and three-time of B.B .

From all results, we conclude that a reaction has occurred between sulfur and bitumenous materials especially hydrocarbon chains of Aromatics and naphthenic rings in sulfur well during Frasch process which leads to an increase in asphaltene percentage and decrease of petrolene.
\end{abstract}

Keywords: Frasch Petrolene $₫$ Asphaltene Silica gel gel

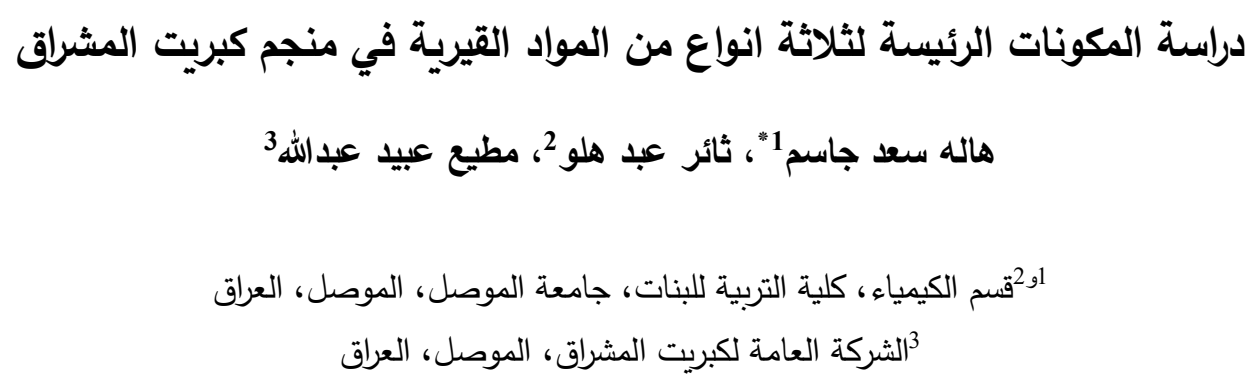

الخلاصة

يتناول هذا البحث دراسة التركيب الكيميائي لثلاث أنواع من المواد القيرية المتواجدة في منجم كبريت المشراق المأخوذة في

ظروف مختلفةB والمتواجدة على عمق 200 م, NB الطبيعية وMB المستخرج بطريقة فراش. أوضحت مطيافية FTIR انخفاض في طول السلاسل الهيدروكاربونية من خلال شدة الحزم العائدة للنظام البارافيني للمواد القيرية المتواجدة في الكبريت 
المنجمي (MB) مقارنة بالمواد القيرية التي تخرج طبيعياً (NB) و (BB)، ولوحظ زيادة مطرودة في نسبة الاسفلتين (MB) (MB) بلغت

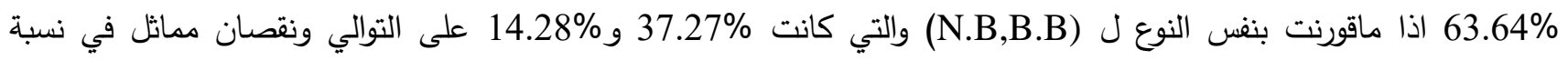
البترولين ولوحظ انخفاض في نسبة الجزء المفصول بواسطة الهكسان خلال عمود السليكا لبترولين MB وبلغ واعت بنفس نوع ل(NB،BB) والتي تثبت 25.06\% و 47.05\% على التوالي في حين ان هناك زيادة في نسبة الجزء المفصول بواسطة الهكسان الحلقي للبترولين MB تزداد ثلاثة وأربعة أضعاف نفس النوع ل (NB،BB) على التوالي ومن خلاد هذه النتائج وربطها بنتائج مطيافية FTIR نستدل أن الكبريت يتفاعل مع التعويضات الهيدروكاربونية على الحلقات الاروماتية والنفثينية في أبار الكبريت خلال أستخراج الكبريت بطريقة الفراش مما يؤدي الى زيادة في نسبةالاسفلتين وانخفاض في نسبة البترولين .

الكلمات المفتاحية : فراش ؛ البترولين؛ الاسفلتين ؛ هلام السليكا

introduction: المقدمة

يعد منجم كبريت المشراق مصدر أساسي للكبريت الرسوبي والذي يقع في العراق على بعد 350km شمال بغداد في منطقة ذات

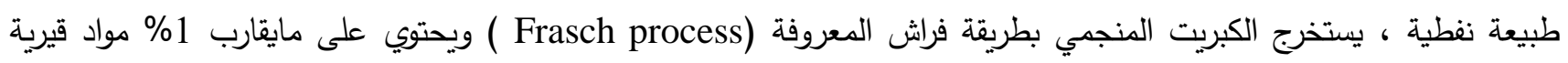
والتي تحد من الاستعمالات الرئيسية للكبريت في انتاج حامض الكبريتيك المركز وخفض قيمته في الأسواق العالمية والتاثير على لكي

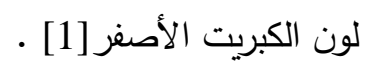
أزيلت المواد القيرية المرافقة للكبريت المنجمي في حقل المشراق بطرائق كيميائية حرارية. وأولى الباحثين موضوع المادة

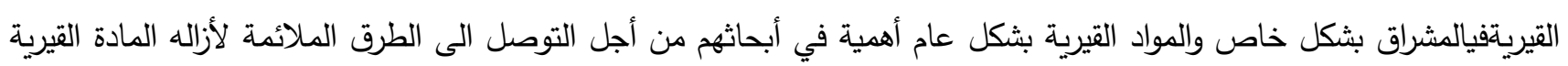
والفوائد الصناعية للمواد القيرية. يتسم تركيبالمادة القيرية بالتعقيد ويختلف من نوع لأخر و درست الصيغة التركيبية للمواد القيرية بأنواعها المختلفة بطرائق متعددة،

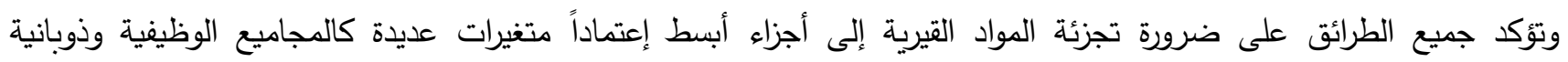

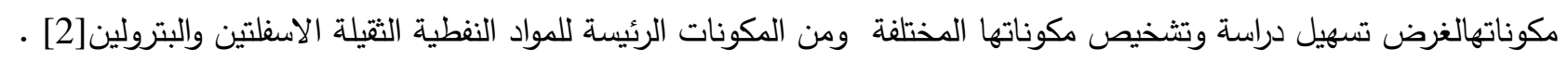

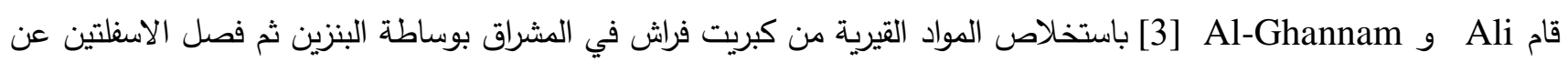
البترولين بالترسيب بوساطة البنتان الطبيعي وكانت نسبة الأسفلتين (80\%) والبترولين (20\%) وتمنام فيناز الثائبة القيرية بانعدامالمواد

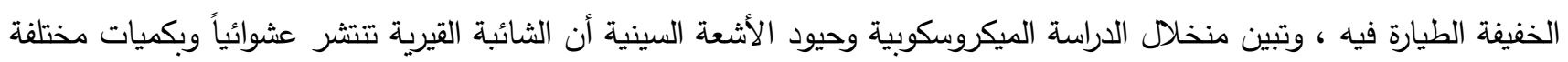
في الصخورالكبريتية. وتمكنت Al- A'araj [4] من إعطاء صورة لمعدل الصيغة الكيميائية لجزيئة المادة القيرية في كبريت المشراق ،بطرائق طيفية و تحليلية مختلفة و ربط نتائجهابحسابات معتمدة منشورة.

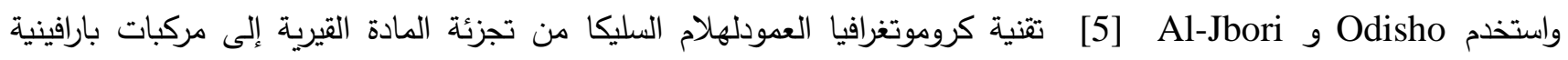
وأروماتية و مواد ثقيلة وأستتنجا أنالتحلل البايولوجي والغسل المائي أثناء هجرة النفط الخام إلى حقل المشراق يؤدي إلى مواد نفطية ثقيلة.

ودرس Al-Jburi [6 المواد القيرية الطبيعية قبل الاستخراج بطريقة فراش وثم فصل الاسفلتين عن البترولين بالترسيب بوساطةبواسطة الهيتان الإعتيادي وكانت نسبةالأسفلتين (20\%) والبترولين (80\%) ومن ثم أستخدام تقنية عمود الكروموتوغرافيا

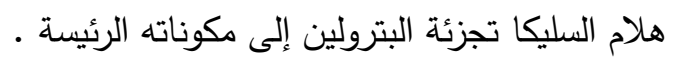

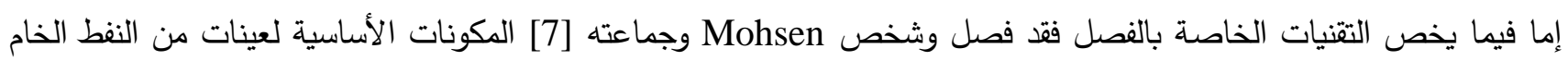

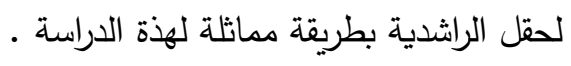


وقامت كل من Nagalakshmi و [8ivasakthi] بترسيب الاسفلتين من النفط الهندي الثقيل الواقع بالجزء الغربي بوساطة الهكسان العتيادي ووجدتا ان نسبته مابين 15-17\% ومن ثم فصل المالتين بوساطة اطيان الى جزئين وفصلتا جزء الزيوت بوساطة هلام السليكا الى برافينات ومركبات عطرية مختلفة باستخدام مذيبات مختلفة الاستقطابية. درس Jairo وجماعته [9] الاسفلتين من خمسة أنواع من النفوط الخام مخففة بالتلوين باستخدام الهبتان الاعتيادي لغرض دراسية دراسة حركية ترسيبه. في هذا البحث تم دراسة تركيب ثلاثة أنواع من المواد القيرية،المواد القيرية الطبيعية والتي تخرج طبيعاً على سطح الأرض (NB)

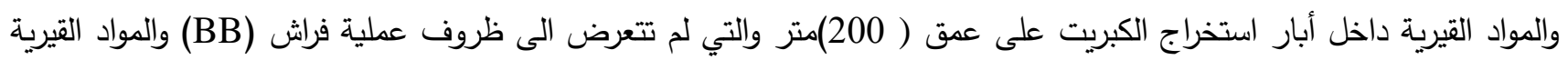

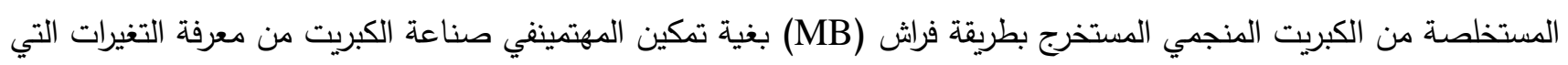
تحصل على هذه المواد لاقتراح الطرائق الملائمة لازالتها.

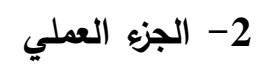
تم الحصول على نماذج من المادة القيرية الطبيعية NBوالصخور الكبريتية والكبريت المنجمي من حقل كبريت المشراق.

2-1-2-إستخلاص المادة القيرية من اللباب الصخري الكبريتي[10]:

\section{Extraction of Bituminous Materials from SulfuricBorehole}

يكسر اللباب الصخري الكبريتي ويفتت إلى اصغر حجم ممكن بعد ذلك تغمر في التولوين تبقى في تماس معه لمدة ثلاث

ساعات مع التحريك بين فترة وآخرى، يلي ذلكترشيح المحلول ثم تقطير المذيب للحصول على. للحصول على المادة القيرية

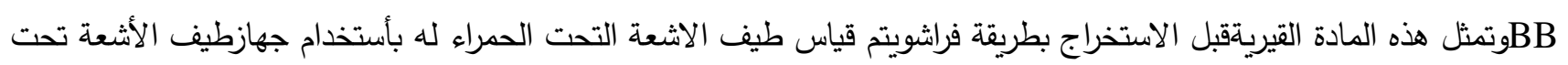

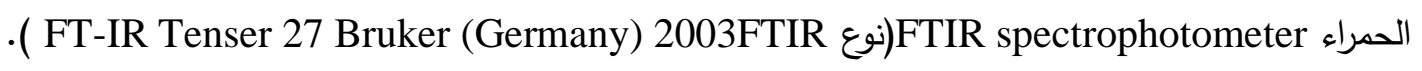

\section{Extraction of Bituminous Materials from Mine sulfur}

2-2-2 استخلاص المادة القيرية من كبريت فراش[11]:

يوزن في بيكر 50 غم من الكبريت الخام ويضاف اليه 50 مل من محلول 20\% هيدروكسيد الصوديومهثم يسخن المزيج

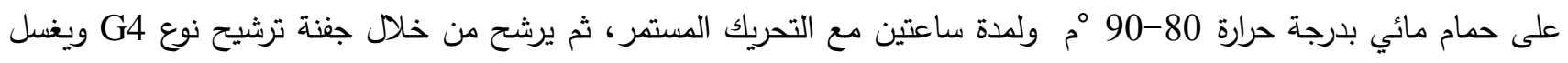

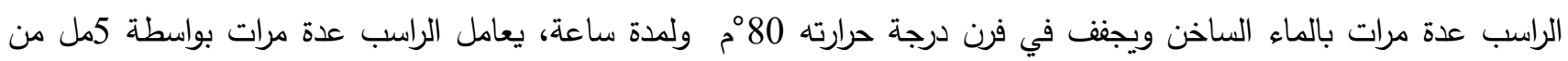
رباعي كلوريد الكاربون حتى يصبح الراشح عديم اللون يقطر وتجفف المادة القيرية بدرجة حرارة 105 مُ ولمدة 24 ساعة ويتم قياس

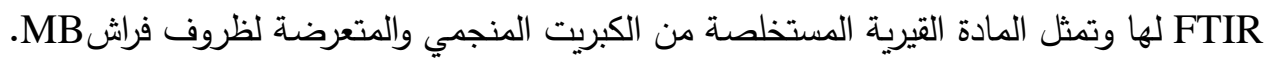
Precipitattion of Asphaltene: 3-2 ترسيب الاسفلتين يوضح في دورق 5غم من المادة القيرية موزونه بدقة و200 مل من الهكسان الاعتيادي بنسبة 40:1 (غم /مل) يربط

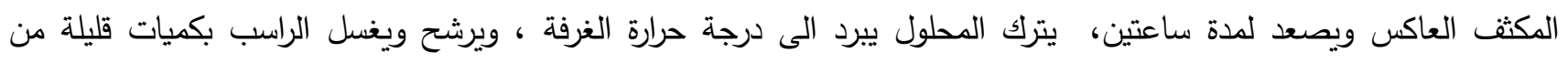

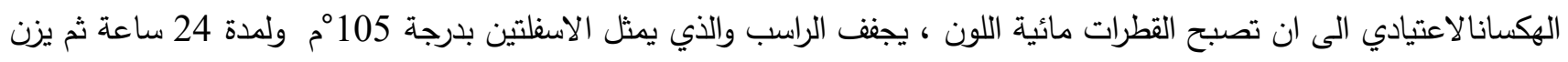
وتحسب النسبة المئوية بعد ذلك يقطر الراشح تقطيرا بسيطا للحصول على البترولين ،ويجفف بدرجة 105م ولمدة 24 ساعة ثم يوزن 
2-2 2-3فاعل المادة|لقيرية الطبيعية مع الكبريت النقي : يؤخذ 99غم من الكبريت ويوضع في بيكر سعة 500 مل ويضاف اليه 1غم من المادة القيرية الطبيعية ئم يوضع على هيتر

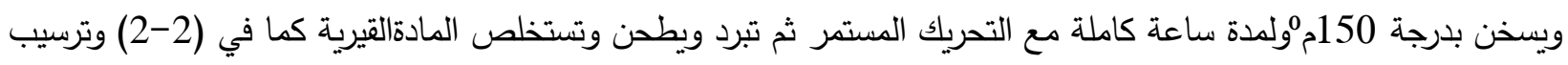

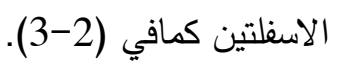

2-4- تجزئة البترولين بواسطة هلام السليكاللأنواع الثلاثه: يوضع في عمودزجاجي (2.2*100)سم خليطا من 50 غم من هلام السليكا (60-120)مش ومنشطة بدرجة 250م ولمدة ثلاث ساعات 30مل من الهبتان الاعتيادي ولضمان تجانس العمود يطرق بلطف بوساطة قطعة مطاطية.يذاب 2 غم من البترولين في 5مل من الهكسان الاعتيادي ويضاف الى العمود بشكل تدريجي وبذلك تكون نسبة البترولين الى هلام السليكا 25:1(وزن التان /وزن)ثم يتم غسل العمود أولا بالهكسان الاعتيادي وبسرعة انسياب 15-20قطرة /دقيقة ثم سايكلوهكسان ثم التولوين وأخيرا الايثانول ويمكن التعرف على انتهاء المادة المزالة بوساطة المذيب بثبات معامل الانكسار وأختفاء اللون من المذيب ثميقطرالمذيب ثم يجفف كل جزء على حدة بدرجة 105ْم ولمدة 24 ساعة ثم يوزن وتحسب النسبة المئوية لكل جزء.

Result and discussion : النتائج والمناقشة - 3.

يشكل وجود المواد القيرية في الكبريت المنجمي المشكلة الرئيسة في الحد من الاستخدامات الأساسية للكبريت سيما في انتاج حامض الكبريتيك المركز إذ يستخدم مايقارب 80\% من الإتتاج العالمي للكبريت فضلا عن خفض فئسئل قيمة الكبريت في الأسواق

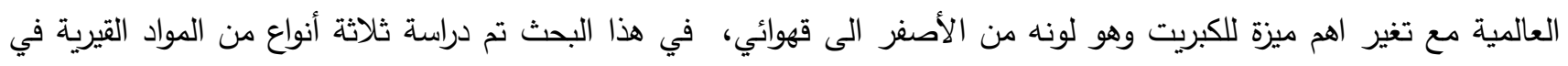

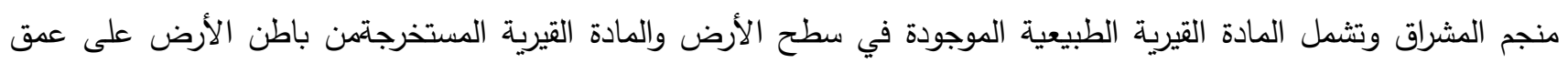

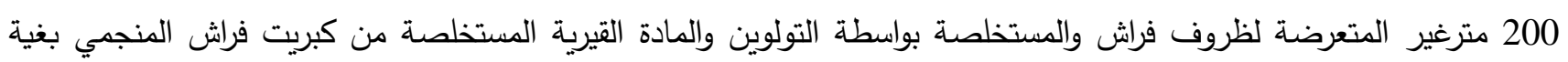

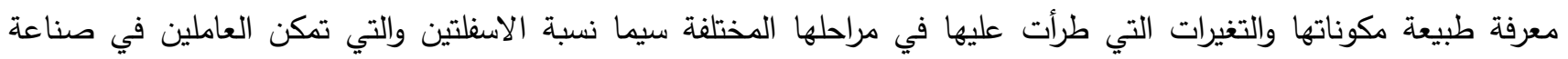
الكبريت أقتراح الطريقة الملائمة في تتقية الكبريت. مكئه

أوضحت مطيافية الاشعة تحت الحمراء FTIR لأنواع الثلاثة الحزم التي تعود للمركبات البارفينية الاروماتية والذرات الهجينية اذا

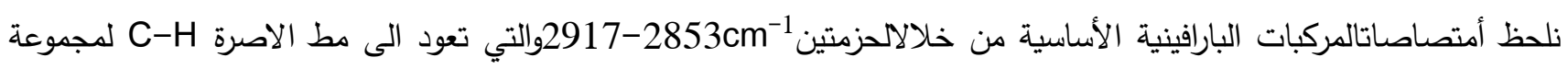

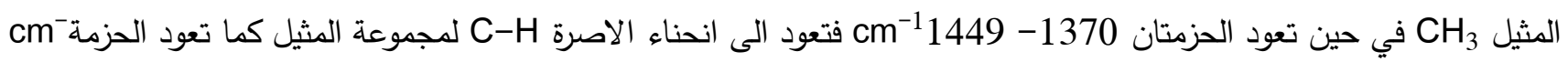

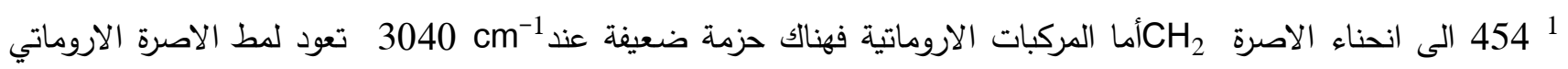

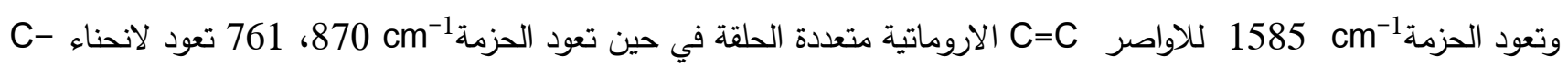
ألاروماتية كما نلحظ وجود الذرات الهجينة من خلال الحزمة 1اتعود لمط الاصرة C=O الاسترية او الثايو أسترية ومن خلال أطياف FTIR الثلاثة نلاحظ أختلافات في شدة الحزم العائدة للمركبات البارافينية أذا قلت شدتها بشكل واضح في المادة القيرية للكبريت المنجمي دلالة على حصول تفاعل للسلاسل البرافينية مع الكبريت وبدرجة حرارة تقارب c 155 وتحولها الى مركبات نفثينية واروماتية وهذا مادعمته النتائج الأخرى المتعلقة بهذا البحث وكما في الثكل (1). 


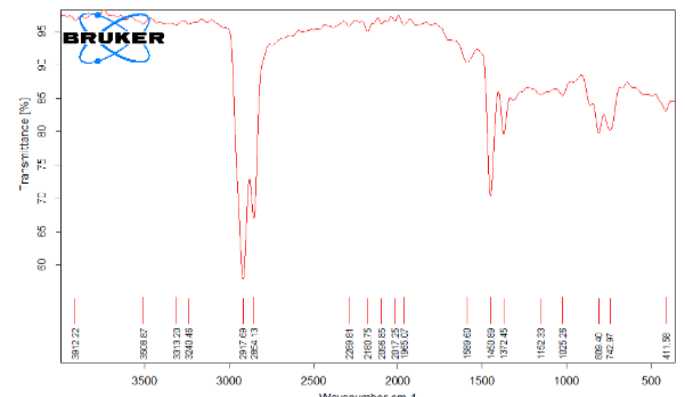

A

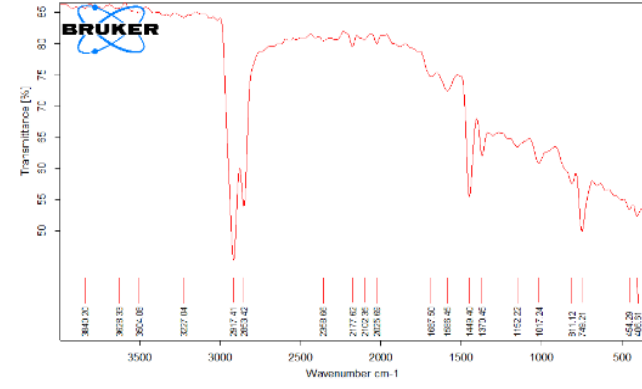

B

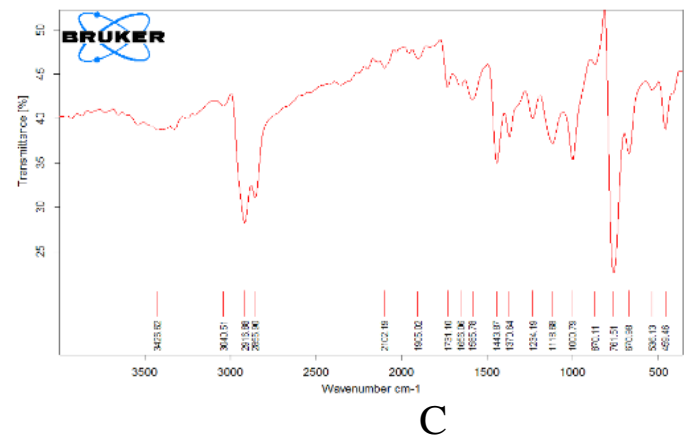

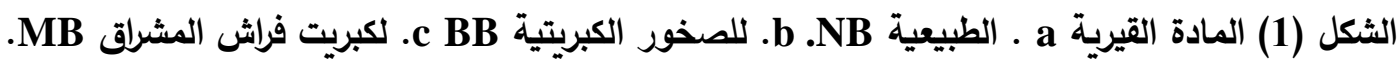

$$
\text { : 1-3 - ترسيب الاسفلتين }
$$

تم ترسيب الاسفلتين وفصله عن البترولين (الجزء الذائب في البرافينات المستقيمة) بوساطة الهكسان وعند درجة الغليان والجدول رقم (1) يوضح نتائج الاسفلتين والبترولين

$$
\text { جدول (1) النسبة المئوية للأسفلتين والبترولين للأنواع الثلاثة في منجم المشراق }
$$

\begin{tabular}{|c|c|c|}
\hline Sample & Asphaltene \% & Petrolene \% \\
\hline N.B & $\mathbf{1 4 . 2 8}$ & $\mathbf{8 5 . 7 2}$ \\
\hline B.B & $\mathbf{3 7 . 2 7}$ & $\mathbf{6 2 . 7 3}$ \\
\hline M.B & $\mathbf{6 3 . 6 4}$ & $\mathbf{3 6 . 3 6}$ \\
\hline
\end{tabular}

نلحظ من جدول(1) زيادة مطردة في كمية الاسفلتين وانخفاض مماثل في كمية البترولين ودلالة على حدوث تغيرات في تركيب

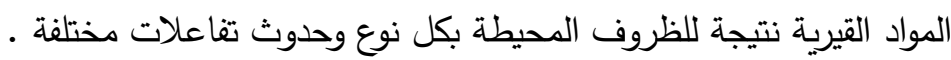

اذا ان المادة القيرية الطبيعية والتي تخرج تلقائيا من باطن الأرض تعاني من ظروف الاكسدة ,والتعريةخلال رحلتها في باطن

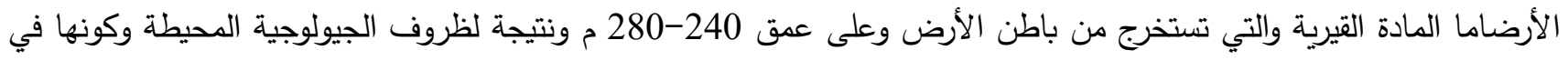
بيئة غنية بالكبريت والمركبات الكبريتية ودرجة الحرارة تقارب

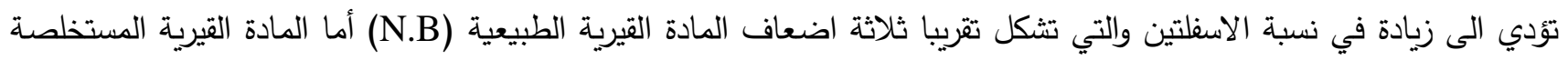
من الكبريت المنجمي فانها تعاني ظروف اقسى من سابقاتها نتيجة لظروف الاستخراج لطريقة فراش والتي تتمثل بدرجة حرارة 
تقارب C 155 وضغط 4 ضغط جوي أدت الى زيادة في كمية الاسفلتين نتيجة تفاعلات الكبريت مع مكونات المادة القيرية ذات

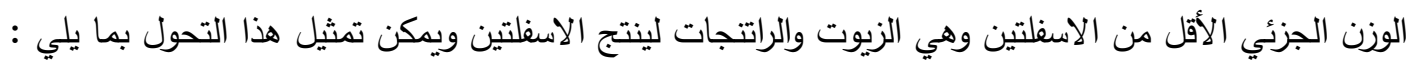

$$
\text { Oils } \rightarrow \text { Resins } \rightarrow \text { Asphaltenes }
$$

ولغرض دعم النتائج وتقسيرها تم أجراء تجربة محاكاة لظروف فراش للمادة القيرية الطبيعية عن طريق تفاعلها مع الكبريت النقي

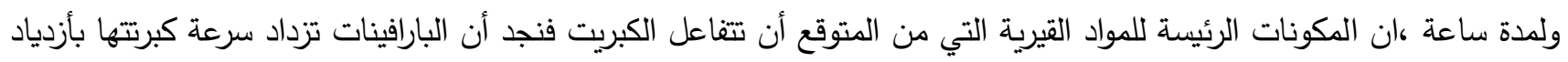

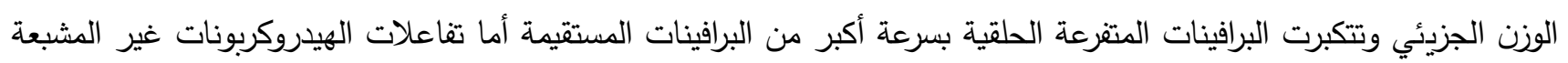
فتتسم بالتعقيدويؤدي تفاعل الراتتجات مع الكبريت الى فقدانها الهيدروجين عن طريق تفاعل إزالة هيدروجينية مما يعمل على تحويل بعض الأجزاء المشبعة الى أجزاء أروماتية مع ظهور بعض الكبريتيدات المعقدة ، تلا ذلك فصل المبل المادة القيرية وتجزئتها الى أسفلتين وبترولين وبلغت نسبة الاسفلتين \% 40.63 والبترولين \% 59.37 يفسر احد الأسباب الرئيسة لارتفاع نسبة الاسفلتين. تم دراسة جزء الاسفلتين للأنواع الثلاثة بواسطة مطيافية FTIR أذ ظهرت حزمة متوسطة الثدة 1590 cm والتي تعود الى لى المركبات الاروماتية ووجد ان تشتت الحزمتين في الاسفلتين المفصول من المادة القيرية (MB) وهذا يدعم تفسيرنا الى نقصان في الصفة البارافينية للمادة القيرية نتيجة تفاعلات

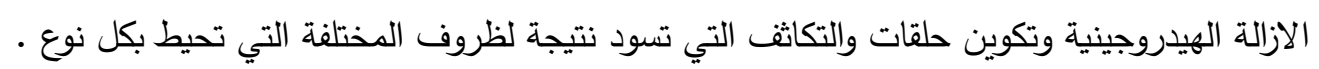

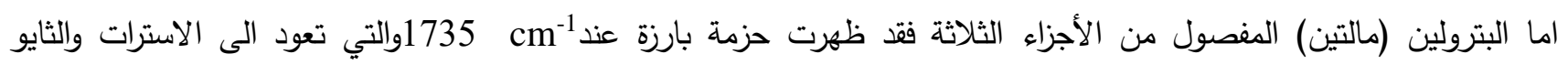

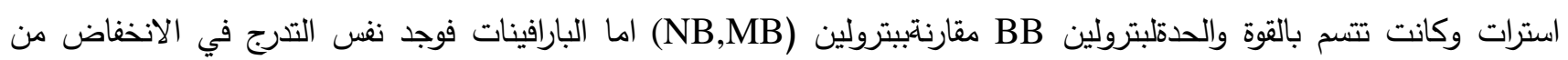
الطبيعية مرورابلبترولين الصخور الكبريتية وأنتهاء الكبريت المنجميوكما في الثكل (2).

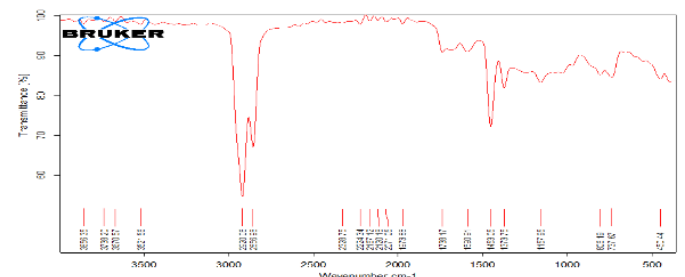

b

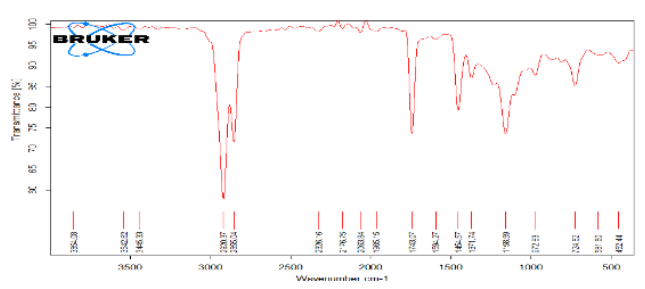

a

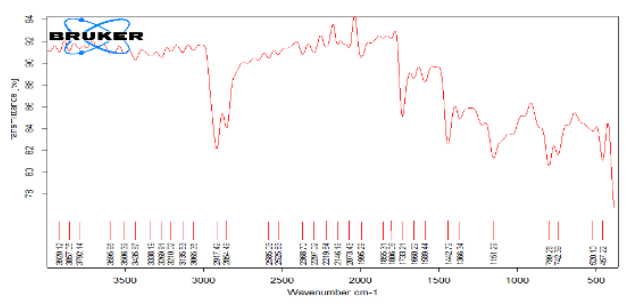

c

الشكل (2) بترولين a . الطبيعية NB. . للصخور الكبريتية BB. c. لكبريت فراش المشراق MB. 
2-3 الفصل الكروموتوغرافي لبترولين ألانواع الثثلاثة :

ولغرض الحصول على نتائج أكثر تفصيلا لتفسير التغيرات التي حصلت في نسبة الاسفلتين والبترولين فقد تم استخدام الفصل

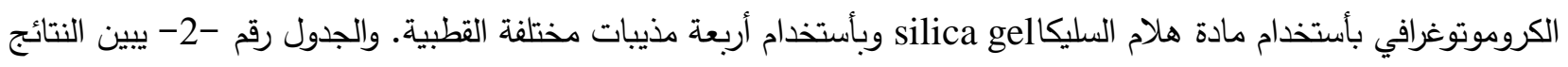
التي حصلنا عليها

جدول (2)

النسب المئوية الوزنية للأجزاء الرئيسة المفصولة من البترولين بأستخام عمود هلام السليكا

\begin{tabular}{|c|c|c|c|c|}
\hline Solvent used & $\begin{array}{c}\text { Expected } \\
\text { Isolated } \\
\text { Materials }\end{array}$ & $\begin{array}{c}\text { Wt\% } \\
\text { N.B }\end{array}$ & $\begin{array}{c}\text { Wt\% } \\
\text { B.B }\end{array}$ & $\begin{array}{c}\text { Wt\% } \\
\text { M.B }\end{array}$ \\
\hline n-Haxane & Paraffinic & 47.85 & 25.06 & 12.49 \\
\hline cyclohexane & $\begin{array}{c}\text { Naphthenic- } \\
\text { Aromatic }\end{array}$ & $\mathbf{1 4 . 4 2}$ & $\mathbf{3 5 . 5 9}$ & $\mathbf{4 7 . 3 6}$ \\
\hline Toluene & Aromatic & 29.66 & $\mathbf{3 3 . 5 2}$ & $\mathbf{3 6 . 1 8}$ \\
\hline Ethanol & $\begin{array}{c}\text { Polar } \\
\text { Aromatic }\end{array}$ & $\mathbf{2 . 2 1}$ & $\mathbf{3 . 2 1}$ & $\mathbf{3 . 8 0}$ \\
\hline Residue & $*$ & $\mathbf{5 . 8 6}$ & $\mathbf{2 . 6 2}$ & $\mathbf{0 . 1 7}$ \\
\hline
\end{tabular}

ومن جدول (2) نلحظ ان الجزء المفصول بوساطة الهكسان وللأنواع الثلاثة حدث انخفاض فيه لبترولين (MB) مقارنة ببترولين

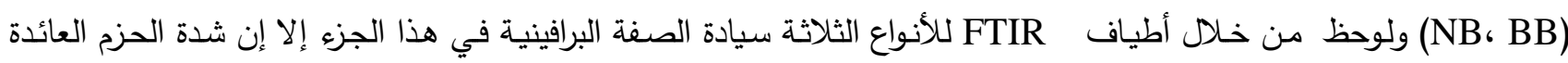

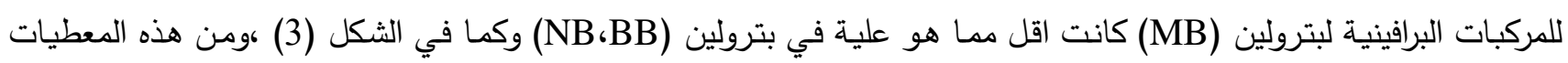

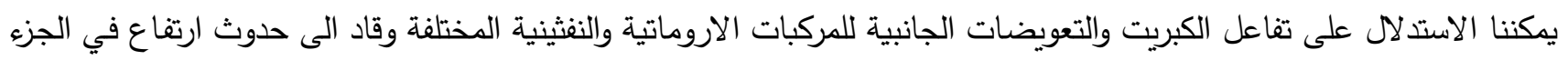

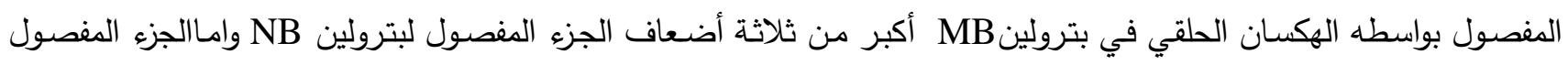

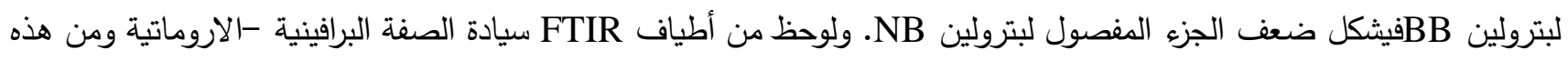

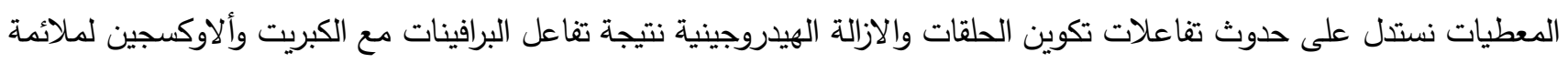

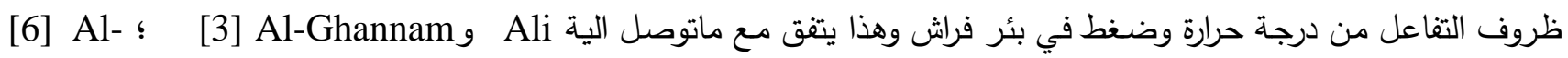
.Jburi 


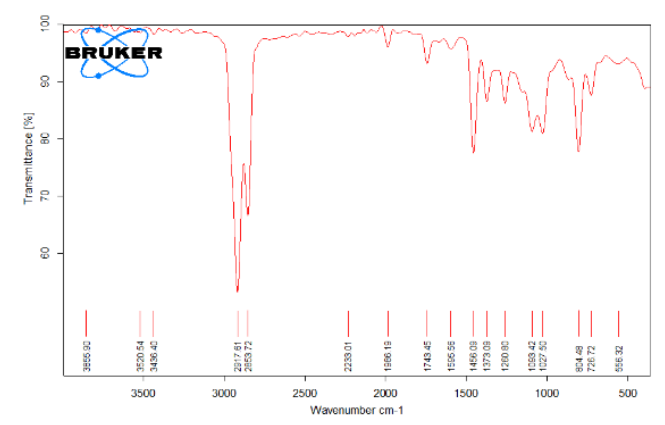

A

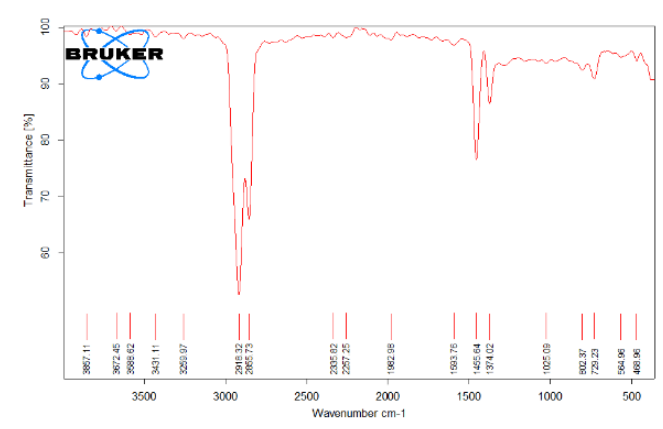

B

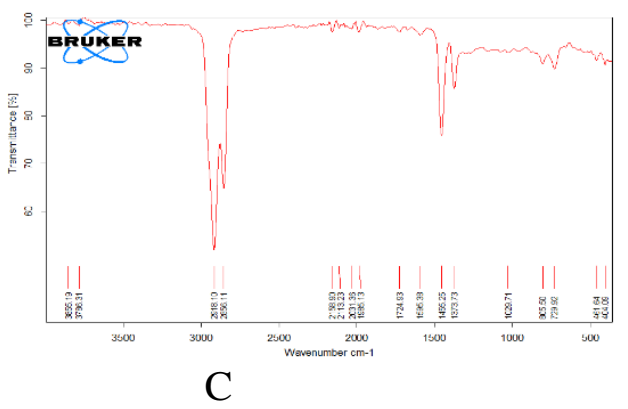

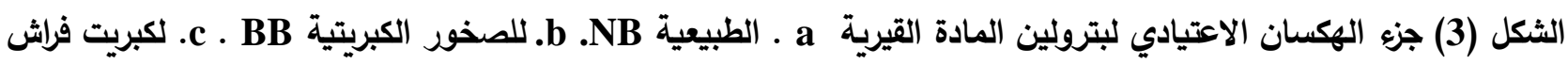
المشراق MB.

ما الأجزاء المفصولة بواسطة التولوين نلحظ زيادة في الجزء مB MB مقارنة بالأجزاء الأخرى نتيجة لتفاعلات الازالة الهيدروجينية وتكوين الحلقات التي تحدث للمركبات البرافينية وجزء من النفثينية ولوحظ من أطياف FTIR انخفاض في حزمة المركبات البارافينية

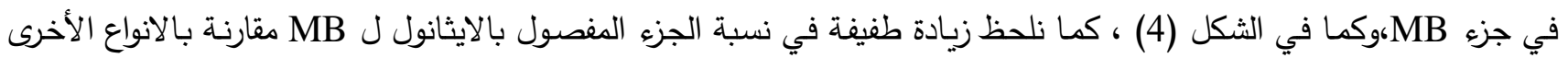
نتيجة تكون مركبات غير متجانسة مستقطبة ونعتقد ان غالبيتها تكون في جزء الاسفلتين. 

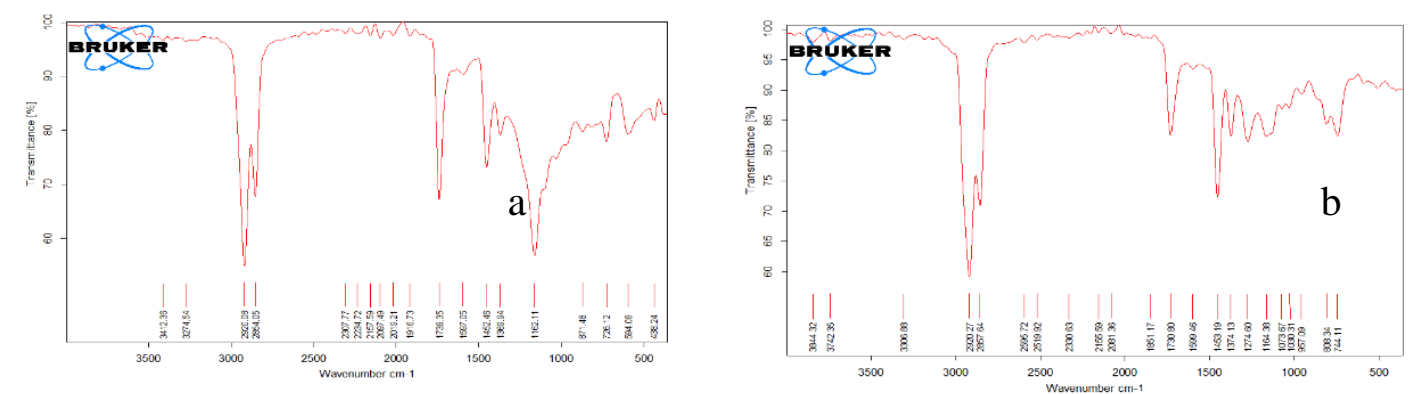

A

B

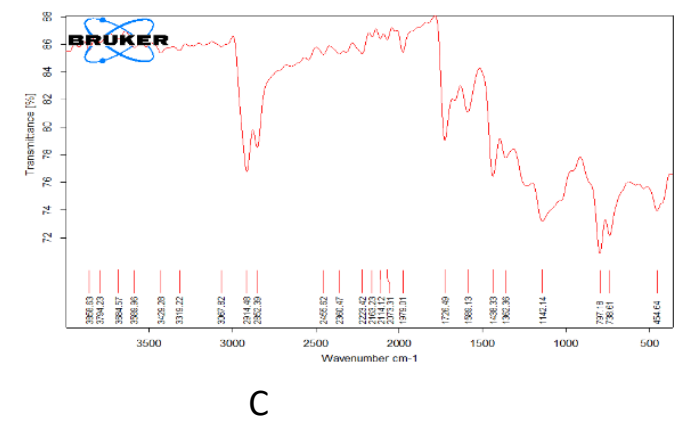

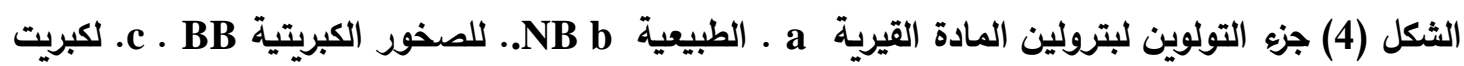

\section{فراش المشراق MB}

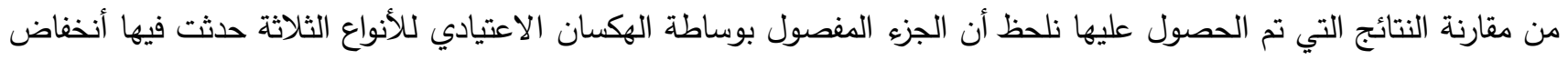
في هذا الجزء تسود فيه الصفة البارافينيةفي MBمقارنتبكل من BB و NB نتيجة لما ذكرناه سابقا ، في حين حدثت زيادة في نسبة النفثينات الاروماتية المفصولة بوساطة الهكسان الحلقي نتيجة لتفاعلات تكوين الحلقات والازاله الهيدروجينية بين الجزء البرافيني والكبريت والاوكسجين والمركبات الكبريتية في حالة تكوين النموذج (B.B) ومع الكبريت بصورة رئيسة في حاله تكوين النموذج

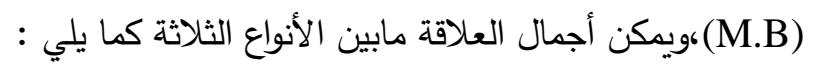

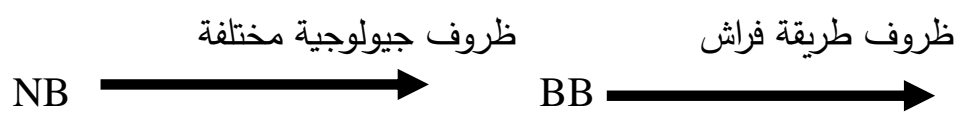
MB

\section{4 الاستنتاجات Conclusion}

من خـل دراسة الأنواع الثثلاثة للمواد القيرية المتواجدة في منجم كبريت المشراق نلحظ زيادة كبيرة في نسبة الاسفلتين وانخفاض واضح في البترولين للمواد القيرية المتواجدة في الكبريت المنجمي (MB) مقارنة بالأنواع الأخرى دلالة تفاعل الكبريت والتعويضات

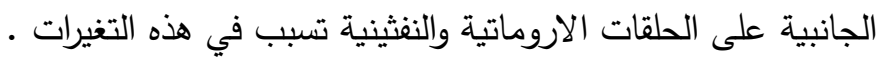




\section{شكر وتقدير Acknowledgement:}

يتقدم الباحثين بالثكر والتقدير الى جامعة الموصل / كلية التربية للبنات / قسم الكيمياء والثركة العامة لكبريت المشراق لتقديم كافة التسهيلات اللازمة لاكمال البحث .

\section{(المصادرReferences:}

1- Al-sawaf F.D.S Economic Geology, 72,608-618 (1977).

2- Oliner C.M, Eric Y.sh., Ahmad .H, Alan G. M. , Asphaltenes Heavy Oils and petroleum springer science Business(2007).

3- Ali, L.H. and Al-Ghannam, K.A. "Bituminous Impurity in the Elemental sulfur from Mishraq Deposit" Fuel, 58, pp. 883-887(1979).

4- Al- A'araj, W.M.. "Developments of Methods for Determination of Bituminous Impurity in Raw Mishraq sulfur and studies on its chemical structure" M.sc. thesis, University of Mosul(1988).(In Arabic)

5- Odisho, K.Y. and Al-Jbori, A.I. "Geochemistry of bitumen from sulfur-bearing, Mishraq mine, northern Iraq"1st Conf. Geoch. Alesc, E94pt, pp. 618-629(1989).

6- Al-Jburi, M.U. (1999). "A study of Sulfur Waste obtained from Raw sulfur Purification by Thermal Method" M.sc. thesis University of Mosul(1999).(In Arabic)

7- Mohsin O. Mohammed, Ibrahim H. Farhan , Tariq Abdul-Jaled . Kirkuk university JournalScientific Studies, V12,Isswe2/March (2017).

8- T. Nagalakshmi, A. Sivasakthi, International Journal of Innovative Technology and Exploring Engineering (IJITEE) ISSN: 2278-3075, Volume-9 Issue-2, December 2019

9- Jairo A.Duran,Flarain F. Schoegg, William Y.ClaudioV.B.F,H. Sott. Energy and Fuels,(2019). 
10- Motea U.A., "A study of The Refinery of Raw Sulfur and its products and their use in chemicals Industry" university Mosul Ph.D. thesis(2011). (In Arabic).

11- Al-Jburi, M.O. “ A guide of quality control in Mishraq sulfur state company “ 2004 